\title{
Human emotion Classification based on Fuzzified Physical Parameters
}

\author{
${ }^{1}$ Swagata Sarkar, ${ }^{2} \mathrm{H}$ Ranganathan
}

\begin{abstract}
There are six basic emotions (sad, happy, fear, angry, surprise, neutral) which can be classified based on different technologies such as image processing, signal processing etc. Facial Emotion detection, fMRI based emotion classification, EEG based emotion analysis are some of the varieties which can diagnose human emotions. In this paper the human emotion classification is done based on physical parameters. The experimental physical parameters are classified by back Propagation algorithm of Artificial Neural Network classifier after fuzzification of data. It is seen that a significant improvement has happened in value of specificity and sensitivity after fuzzification of data.
\end{abstract}

Key Words: Artificial Neural Network, Fuzzification, human emotion, Sensitivity, Specificity

\section{Introduction}

Human Emotion analysis is a very popular topic of interest. If emotion can be classified properly many psychological problems can be detected at the earliest and further complications can be prevented and cured fully. In reality six distinguishable basic emotions exist. Other than these, there are lots of compound emotions present which are difficult to classify properly. The emotion identifications are done by Facial Image Processing, fMRI Image Processing, EEG [1] Signal Processing as well as based on Physical Parameters. But in this work experimental dataset is preprocessed and fuzzified. The fuzzified data is then classified with the help of Back Propagation algorithm. Fuzzification is process where the data boundaries are defined very clearly. In this work 14 experimental parameters and their existing emotional ranges are considered. All the fourteen parameters have significant impact on human emotions. The definition and ranges of parameters are given below.

\footnotetext{
${ }^{1}$ Swagata Sarkar

Research scholar, Sathyabama University

Chennai, India

${ }^{2} \mathrm{H}$ Ranganathan

Professor, Gojan School of Management and

Technology, Chennai, India
}

1. Electroencephalography (EEG): EEG measurements are given in frequency ranges. It has four linguistic variables, alpha $(13-15 \mathrm{~Hz})$, beta $(7.5-13 \mathrm{~Hz})$, Theta $(2.5-8)$, delta $(<4 \mathrm{~Hz})$.

2. Heart Rate (HR): The ranges for heart rate with three fuzzy linguistic variables are Low heart rate(LHR) from 20 to $70 \mathrm{BPM}$, Normal Heart Rate (NHR) 45 to 100 BPM, High Heart Rate (HHR) from 84 to 120 BPM.

3. Hear Rate Variability (HRV): HRV has three fuzzy linguistic variables. Those are High HRV (HHRV) from 0.15 to $0.4 \mathrm{~Hz}$, Low HRV (LHRV) from 0.04 to $0.15 \mathrm{~Hz}$, Very Low HRV (VLHRV) from 0.003 to $0.4 \mathrm{~Hz}$.

4. Pre-Ejection Period (PEP): The three fuzzy linguistic variables for PEP are Low PEP (LPEP) from 0 to $800 \mathrm{~ms}$, Normal PEP (NPEP) from 0 to $1000 \mathrm{~ms}$ and High PEP (HPEP) from 500 to $1100 \mathrm{~ms}$.

5. Stroke volume (SV): Three linguistic variables are Low SV (LSV) from 10 to $144 \mathrm{ml}$. Normal SV (NSV) from 10 to $250 \mathrm{ml}$, High SV (HSV) from 240 to $400 \mathrm{ml}$.

6. Systolic blood pressure (SBP): Three linguistic variables for SBP are Low SBP (LSBP) from 100 to $121 \mathrm{Hg}$, Normal SBP (NSBP) from 110 to $134 \mathrm{Hg}$. and High SBP (HSBP) from 120 to 147 $\mathrm{Hg}$.

7. Diastolic blood pressure (DBP): Three linguistic variables for DBP are Low DBP (LDBP) from 77 to $87 \mathrm{Hg}$, Normal DBP (NDBP) from 81 to $91 \mathrm{Hg}$. and High DBP (HDBP) from 81 to 91 $\mathrm{Hg}$.

8. Skin Conductance Response (SCR): Three linguistic variables for SCR are Low SCR (HSCR) from 0.85 to $1.5 \mathrm{~ms}$.

9. (LSCR) from 0 to $0.2 \mathrm{~ms}$, Normal SCR (NSCR) from 0.1 to $1 \mathrm{~ms}$ and High SCR

10. Tidal Volume (TV): Three linguistic variables for TV are Rapid TV (RTV) from $100 \mathrm{ml} / \mathrm{breath}$ to $150 \mathrm{ml} /$ breath, Quiet TV (QTV) from 200 
$\mathrm{ml} / \mathrm{breath}$ to $750 \mathrm{ml} / \mathrm{breath}$ and $600 \mathrm{ml} / \mathrm{breath}$ to $1200 \mathrm{ml} / \mathrm{breath}$.

11. Oscillatory Resistance (OR): Three linguistic variables for RO are Low RO (LRO) from 0 to 0.49 , Normal RO (NRO) from 0.4 to 0.88 and High RO (HRO) from 0.5 to 1 .

12. Respiration Rate (RR): Three linguistic variables for RR are Low RR (LRR) from 5 to 10 breath/minute, Normal RR (NRR) from 7 to 23 breath/minute and High RR (HRR) from 15 to 24 breath/minute.

13. Non Specific Skin Conductance Response (NSCR): Three linguistic variables for NSCR are Low NSCR (LNSCR) from 0 to 2 per minute, Normal NSCR (NNSCR) from 1 to 3 per minute and High NSCR (HNSCR) from 2 to 5 per minute.

14. Skin Conductance level (SCL): Three linguistic variables for SCL are Low SCL (LSCL) from 0 to $2 \mathrm{~ms}$, Normal SCL (NSCL) from 2 to $25 \mathrm{~ms}$ and High SCL(HSCL) from 20 to $25 \mathrm{~ms}$.

15. Finger Temperature (FT): Three linguistic variables for FT are Low FT (LFT) from 65 to $75{ }^{\circ} \mathrm{F}$, Normal FT (NFT) from 75 to $85{ }^{\circ} \mathrm{F}$ and High FT (HFT) from 80 to $90^{\circ} \mathrm{F}$.

\section{Fuzzification:}

The flow diagram used is shown in figure 1 .

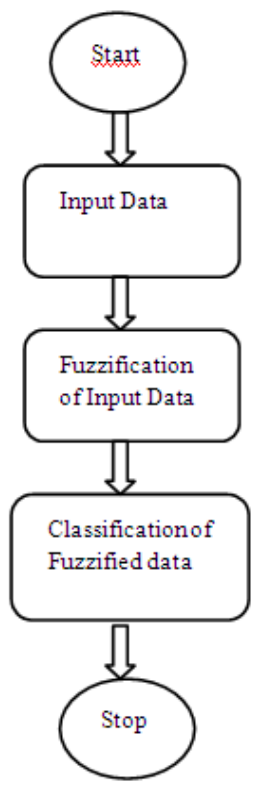

Fig.1. Flow diagram of Physical parameter based emotion analysis
Fuzzification is the first step in the fuzzy inferencing process[5]. This involves a domain transformation where crisp inputs are transformed into fuzzy inputs. Crisp inputs are exact inputs such as temperature, pressure, rpm's, etc. measured by sensors and passed into the system for processing. Each crisp input that is to be processed by the FIU has its own group of membership functions or sets to which they are transformed. This group of membership functions exists within a universe of discourse that holds all relevant values that the crisp input can possess. The following shows the structure of membership functions within a universe of discourse for a crisp input.

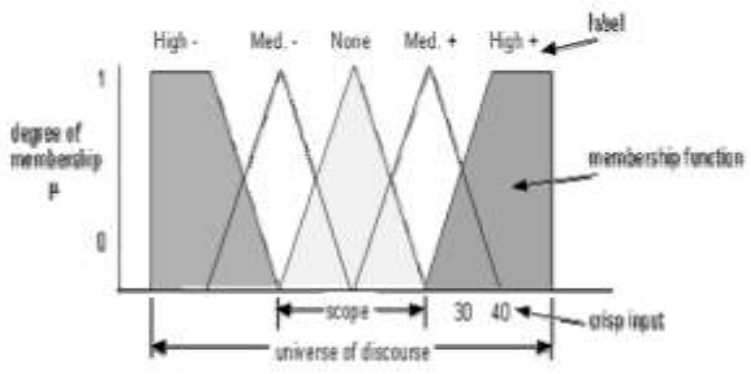

Fig. 2. Membership Function Structure

where: degree of membership: degree to which a crisp value is compatible to a membership function, value from 0 to 1 , also known as truth value or fuzzy input. Membership function, MF: defines a fuzzy set by mapping crisp values from its domain to the sets associated degree of membership. Crisp inputs: distinct or exact inputs to a certain system variable, usually measured parameters external from the control system, e.g. 6 Volts. Label: descriptive name used to identify a membership function. Scope: or domain, the width of the membership function, the range of concepts, usually numbers, over which a membership function is mapped. Universe of discourse: range of all possible values, or concepts, applicable to a system variable. When designing the number of membership functions for an input variable, labels must initially be determined for the membership functions. The number of labels correspond to the number of regions that the universe should be divided, such that each label describes a region of behavior. A scope must be assigned to each membership function that numerically identifies the 
Proc. of The Fifth Intl. Conf. On Advances in Computing, Electronics and Electrical Technology - CEET 2016

Copyright () Institute of Research Engineers and Doctors, USA .All rights reserved.

ISBN: 978-1-63248-087-3 doi: 10.15224/ 978-1-63248-087-3-58

range of input values that correspond to a label. The shape of the membership function should be representative of the variable. However this shape is

Table 1. Representation of an imaginary example of a decision matrix.

\begin{tabular}{|c|c|c|c|c|c|}
\hline & \multicolumn{4}{|c|}{ laput Y } \\
\hline & & $1.0 \mathrm{~W}$ & NOFWAAL & Hilit & VERY HIIF \\
\hline \multirow{4}{*}{ ל } & LOW & Lou & High & High & High \\
\hline & NORMAL & Low & Low & Mediun & Meduint \\
\hline & HIGH & Low & Low & Low & Low \\
\hline & VERY HIGH & Low & Low & Low & Low \\
\hline
\end{tabular}

\section{Artificial Neural Network (ANN)}

One type of network sees the nodes as 'artificial neurons'. These are called artificial neural networks (ANNs). An artificial neuron, as shown in figure 3, is a computational model inspired in the natural neurons. Natural neurons receive signals through synapses located on the dendrites or membrane of the neuron. When the signals received are strong enough (surpass a certain threshold), the neuron is activated and emits a signal though the axon. This signal might be sent to another synapse, and might activate other neurons.

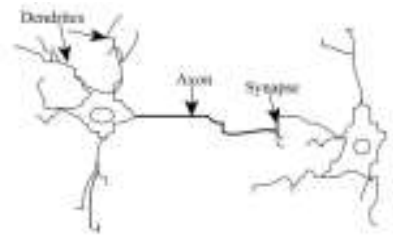

Fig. 3. Natural Neurons

The complexity of real neurons is highly abstracted when modeling artificial neurons, as shown in figure 4. These basically consist of inputs (like synapses), which are multiplied by weights (strength of the respective signals), and then computed by a mathematical function which determines the activation of the neuron. Another function (which may be the identity) computes the output of the artificial neuron (sometimes in dependence of a certain threshold). ANNs combine artificial neurons in order to process information. also restricted by the computing resources available. Complicated shapes require more complex descriptive equations or large lookup tables.

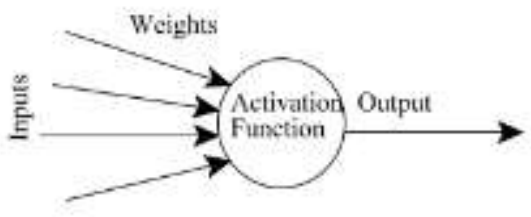

Fig. 4. An Artificial Neuron

\section{The Back Aropagation Algorithm}

The back propagation algorithm (Rumelhart and McClelland, 1986) is used in layered feed-forward ANNs. This means that the artificial neurons are organized in layers, and send their signals "forward", and then the errors are propagated backwards. The network receives inputs by neurons in the input layer, and the output of the network is given by the neurons on an output layer[6]. There may be one or more intermediate hidden layers. The back propagation algorithm uses supervised learning, which means that we provide the algorithm with examples of the inputs and outputs we want the network to compute, and then the error (difference between actual and expected results) is calculated. The idea of the back propagation algorithm is to reduce this error, until the ANN learns the training data. The training begins with random weights, and the goal is to adjust them so that the error will be minimal.

The activation function of the artificial neurons in ANNs implementing the back propagation algorithm is a weighted sum (the sum of the inputs $\mathrm{x}$ multiplied by their ji respective weights $\mathrm{w}$ ):

$A_{j}(\bar{x}, \bar{w})=\sum_{i=0}^{n} x_{i} w_{j t}$

(1)

We can see that the activation depends only on the inputs and the weights. If the output function would be the identity (output=activation), then the neuron would be called linear. But these have severe limitations. The most common output function is the sigmoid function: 
Proc. of The Fifth Intl. Conf. On Advances in Computing, Electronics and Electrical Technology - CEET 2016

Copyright $\odot$ Institute of Research Engineers and Doctors, USA .All rights reserved.

ISBN: 978-1-63248-087-3 doi: 10.15224/ 978-1-63248-087-3-58

$$
O_{j}(\bar{x}, \bar{w})=\frac{1}{1+e^{A(\bar{x}, \bar{w})}}
$$

Fuzzification is used to get more precise and well defined data. After preprocessing and fuzzification the data is given for classification with the help of Back Propagation Network (BPN) algorithm. Comparison is done based on preprocessed data without Fuzzification and preprocessed data with fuzzification. It is seen that sensitivity and specificity improve for preprocessed data with fuzzified input.

\section{Efficiency analysis}

The analysis of 50 subjects is carried out. The results are encouraging.

The following terms are fundamental to understanding the utility of biomedical parameter based tests:

1. True positive: the subject has the emotion and the test is positive.

2. False positive: the subject does not have the emotion but the test is positive.

3. True negative: the subject does not have the emotion and the test is negative

4. False negative: the subject has the emotion but the test is negative.

\section{Sensitivity}

The sensitivity of a clinical test refers to the ability of the test to correctly identify those patients with the disease.

$$
\text { Sensitivity }=\frac{\text { True positives }}{\text { True positives }+ \text { False negatives }}
$$

\section{Specificity}

Table 2 Classification result for input non fuzzified data
The specificity of a clinical test refers to the ability of the test to correctly identify those patients without the disease.

$$
\text { Specificity }=\frac{\text { True negatives }}{\text { True negatives }+ \text { False positives }}
$$

\section{Positive predictive value}

The PPV of a test is a proportion that is useful to clinicians since it answers the question: "How likely is it that this patient has the disease given that the test result is positive?'

Positive predictive value $=\frac{\text { True positives }}{\text { True positives }+ \text { False positives }}$

\section{Negative predictive value}

The NPV of a test answers the question: 'How likely is it that this patient does not have the disease given that the test result is negative?'

Negative predictive value $=\frac{\text { True negatives }}{\text { True negatives }+ \text { False negatives }}$

\section{Likelihood ratio}

A final term sometimes used with reference to the utility of tests is the likelihood ratio. This is defined as how much more likely is it that a patient who tests positive has the disease compared with one who tests negative.

Likelihood ratio $=\frac{\text { Sensitivity }}{1-\text { Specificity }}$

\section{Results \& Discussions:}

In this paper emotion analysis is done for 50 subjects. Six emotions are taken into consideration. Total number of data considered for classification is 50 .

\begin{tabular}{|clcccc|}
\hline S. No. & $\begin{array}{c}\text { Types of } \\
\text { Emotions }\end{array}$ & $\begin{array}{c}\text { True Positive } \\
\text { (TP) }\end{array}$ & $\begin{array}{c}\text { True Negative } \\
\text { (TN) }\end{array}$ & $\begin{array}{c}\text { False Positive } \\
\text { (FP) }\end{array}$ & $\begin{array}{c}\text { False Negative } \\
\text { (FN) }\end{array}$ \\
\hline $\mathbf{1}$ & Happy & 21 & 8 & 10 & 11 \\
\hline $\mathbf{2}$ & Sad & 18 & 11 & 12 & 9 \\
\hline $\mathbf{3}$ & Fear & 27 & 13 & 3 & 7 \\
\hline $\mathbf{4}$ & Angry & 20 & 15 & 13 & 2 \\
\hline $\mathbf{5}$ & Neutral & 22 & 12 & 12 & 4 \\
\hline $\mathbf{6}$ & Surprise & 15 & 17 & 10 & 8 \\
\hline
\end{tabular}


Proc. of The Fifth Intl. Conf. On Advances in Computing, Electronics and Electrical Technology - CEET 2016

Copyright ( $)$ Institute of Research Engineers and Doctors, USA .All rights reserved.

ISBN: 978-1-63248-087-3 doi: 10.15224/ 978-1-63248-087-3-58

Table 3 Classification result for input fuzzified data

\begin{tabular}{|llcccc|}
\hline S. No. & $\begin{array}{r}\text { Types of } \\
\text { Emotions }\end{array}$ & $\begin{array}{c}\text { True Positive } \\
\text { (TP) }\end{array}$ & $\begin{array}{c}\text { True Negative } \\
\text { (TN) }\end{array}$ & $\begin{array}{c}\text { False Positive } \\
\text { (FP) }\end{array}$ & $\begin{array}{c}\text { False Negative } \\
\text { (FN) }\end{array}$ \\
\hline $\mathbf{1}$ & Happy & 25 & 17 & 6 & 2 \\
\hline $\mathbf{2}$ & Sad & 29 & 15 & 1 & 5 \\
\hline $\mathbf{3}$ & Fear & 30 & 18 & 1 & 1 \\
\hline $\mathbf{4}$ & Angry & 26 & 19 & 5 & 1 \\
\hline $\mathbf{5}$ & Neutral & 27 & 20 & 3 & 2 \\
\hline $\mathbf{6}$ & Surprise & 28 & 12 & 7 & 3 \\
\hline
\end{tabular}

Table 4 Analysis of different emotions for non fuzzified input

\begin{tabular}{|c|c|c|c|c|c|c|c|c|c|c|c|}
\hline $\begin{array}{l}\text { S. } \\
\text { No. }\end{array}$ & $\begin{array}{l}\text { Types of } \\
\text { Emotions }\end{array}$ & $\begin{array}{l}\text { Specificity } \\
\text { (in \%) }\end{array}$ & $\begin{array}{c}\text { Average } \\
\text { Specificity } \\
\text { (in \%) }\end{array}$ & $\begin{array}{l}\text { Sensitivity } \\
\text { (in \%) }\end{array}$ & $\begin{array}{l}\text { Average } \\
\text { Sensitivity } \\
\text { (in 96) }\end{array}$ & $\begin{array}{l}\text { Likelihood } \\
\text { Ratio (in \%) }\end{array}$ & $\begin{array}{l}\text { Average } \\
\text { Likelihood } \\
\text { (in 9\%) }\end{array}$ & $\begin{array}{l}\text { Positive } \\
\text { Predictive } \\
\text { value (in } \\
\text { \%) }\end{array}$ & $\begin{array}{c}\text { Average } \\
\text { Positive } \\
\text { Predictive } \\
\text { Value (in } \\
\% \text { ) }\end{array}$ & $\begin{array}{c}\text { Negative } \\
\text { Predictive } \\
\text { value (in } \\
\% \text { ) }\end{array}$ & $\begin{array}{c}\text { Average } \\
\text { Negative } \\
\text { Predictive } \\
\text { Value (in } \\
\text { \%) }\end{array}$ \\
\hline 1 & Happy & 44.44 & \multirow{6}{*}{75.07} & 63.63 & \multirow{6}{*}{56.67} & 1.13 & \multirow{6}{*}{2.00885} & 67.74 & \multirow{6}{*}{67.17} & 42.10 & \multirow{6}{*}{65.55} \\
\hline 2 & Sad & 47.82 & & 66.66 & & 1.2775 & & 60 & & 55 & \\
\hline 3 & Fear & 81.25 & & 79.41 & & 4.2352 & & 90 & & 65 & \\
\hline 4 & Angry & 53.57 & & 90.90 & & 1.9577 & & 60.6 & & 88.23 & \\
\hline 5 & Neutral & 50 & & 84.61 & & 1.6922 & & 64.7 & & 75 & \\
\hline 6 & Surprise & 62.96 & & 65.21 & & 1.7605 & & 60 & & 68 & \\
\hline
\end{tabular}

Table 5 Analysis of different emotions for fuzzified input

\begin{tabular}{|c|c|c|c|c|c|c|c|c|c|c|c|}
\hline $\begin{array}{r}\text { S. } \\
\text { No. }\end{array}$ & $\begin{array}{l}\text { Types of } \\
\text { Emotions }\end{array}$ & $\begin{array}{l}\text { Specificity } \\
\text { (in \%) }\end{array}$ & $\begin{array}{c}\text { Average } \\
\text { Specificity } \\
\text { (in } \% \text { ) }\end{array}$ & $\begin{array}{l}\text { Sensitivity } \\
\text { (in 9\%) }\end{array}$ & $\begin{array}{c}\text { Average } \\
\text { Sensitivity } \\
\text { (in \%) }\end{array}$ & $\begin{array}{l}\text { Likelihood } \\
\text { Ratio (in \%) }\end{array}$ & $\begin{array}{l}\text { Average } \\
\text { Likelihoo } \\
\text { d (in \%) }\end{array}$ & $\begin{array}{l}\text { Positive } \\
\text { Predicti } \\
\text { ve value } \\
\text { (in } \% \text { ) }\end{array}$ & $\begin{array}{l}\text { Average } \\
\text { Positive } \\
\text { Predictiv } \\
\text { eValue } \\
\text { (in \%) }\end{array}$ & $\begin{array}{l}\text { Negativ } \\
e \\
\text { Predicti } \\
\text { ve value } \\
\text { (in \%) }\end{array}$ & $\begin{array}{l}\text { Average } \\
\text { Negative } \\
\text { Predictive } \\
\text { Value (in } \\
\% \text { ) }\end{array}$ \\
\hline 1 & Happy & 73.91 & \multirow{3}{*}{81.94} & 92.59 & \multirow{3}{*}{92.39} & 3.5488 & \multirow{3}{*}{8.2937} & 80.6 & \multirow{3}{*}{87.97} & 89.47 & \multirow{3}{*}{87.51} \\
\hline 2 & Sad & 93.75 & & 85.29 & & 13.6464 & & 96.66 & & 75 & \\
\hline 3 & Fear & 94.73 & & 96.77 & & 18.3624 & & 96.77 & & 94.73 & \\
\hline 4 & Angry & 79.16 & & 96.29 & & 4.62 & & 83.8 & & 95 & \\
\hline 5 & Neutral & 86.95 & & 93.10 & & 7.134 & & 90 & & 90.9 & \\
\hline 6 & Surprise & 63.15 & & 90.32 & & 2.451 & & 80 & & 80 & \\
\hline
\end{tabular}

Table 6 Comparison of different emotions for fuzzified \& non-fuzzified input

\begin{tabular}{|c|c|c|c|c|c|c|}
\hline $\begin{array}{l}\text { S. } \\
\text { No. }\end{array}$ & $\begin{array}{l}\text { Input } \\
\text { types }\end{array}$ & $\begin{array}{l}\text { Average } \\
\text { Sensitivity }\end{array}$ & $\begin{array}{c}\text { Average } \\
\text { Specificity }\end{array}$ & $\begin{array}{c}\text { Average } \\
\text { Likelihood } \\
\text { Ratio }\end{array}$ & $\begin{array}{c}\text { Average } \\
\text { Positive } \\
\text { predictive } \\
\text { value }\end{array}$ & $\begin{array}{c}\text { Average } \\
\text { Negative } \\
\text { predictive } \\
\text { value }\end{array}$ \\
\hline 1 & $\begin{array}{l}\text { Non } \\
\text { Fuzzified } \\
\text { Inputs }\end{array}$ & 75.07 & 56.67 & 2.00885 & 67.17 & 65.55 \\
\hline 2 & $\begin{array}{l}\text { Fuzzzified } \\
\text { Inputs }\end{array}$ & 81.94 & 92.39 & 8.2937 & 87.97 & 87.51 \\
\hline
\end{tabular}




\section{Conclusion}

In this paper the comparison between fuzzified input and non fuzzified input is done. It is seen that specificity, sensitivity and Likelihood ratio are improved by respectively.

\section{Acknowledgement}

Author would like to thank the research institute for their continuous support in all aspect.

\section{References}

[1] Nie D, Wang X, Shi L \& Lu B 2011, "EEG-based Emotion Recognition during Watching Movies ",International IEEE EMBS Conference on Neural Engineering Cancun, Mexico, pp $667-670$.

[2] Owaied H \& Abu-Arr'a M 2007, 'Functional

Model of Human System an Knowledge Base System', The International Conference on Information \& Knowledge Engineering, pp. 158 - 161

[3] Kreibig S 2010, 'Autonomic nervous system activity in emotion: A review', biological Psychology 84, pp. 394-421

[4] Zadah L, 1965, 'Fuzzy Sets', Ntional Science Foundation under Grant, U.S.

[5] Negnevitsky M. 2005,'Fuzzy Expert System', 2nd ed, "Artificial Intelligent A Guide to Intelligent Systems", Pearson Education, England.

[6] Abraham A 2005, 'Artificial Neural Networks', Handbook of Measuring System Design, USA, John Wiley \& Sons, Ltd, pp.901-908.

[7] Silberstein R 1990, 'Electroncephalographic Attention Monitor', US patent 4,955,388

[8] Timmons N \& Scanlon W 2005, 'Analysis of the

Performance of IEEE 802.15.4 for Medical Sensor Body Area Networking', Sensor and Ad Hoc Communications and Networks, 2004. IEEE SECON 2004. First Annual IEEE Communications Society Conference, Ireland.pp.1-4.

[9] Ohtaki Y, Suzuki A \& Papatetanou 2009,

'Integration of psycho - Physiological and

Behavioral Indicators with Ambulatory Tracking of Momentary Indoor Activity Assessment', ICROS - SIC, International Joint conference 2009, Japan pp. 499-502.

[10] Petrushin V \& Gove B 2002, 'Detecting Emotions Using Voice Signal Analysis', US patent 7,222,075,B2.

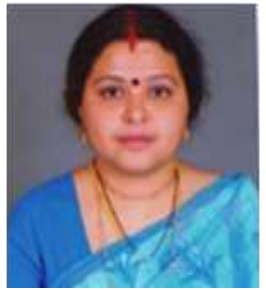

Swagata B Sarkar received her AMIE with gold medal from Institutions of Engineers India. She has completed ME from West Bengal University of Technology. Her area of interest is networking, antenna, mobile communication.

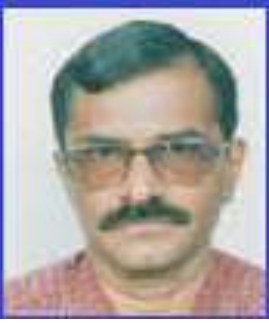

H. Ranganathan received the B.E. M.Sc. (Eng.) and $\mathrm{Ph} \mathrm{D}$ from the College of Engineering, Chennai, India, in 1975, 1978 and 2007 respectively. From 1978 to 2000, he was involved in the installation and maintenance of various computers and development of hardware and software solutions for many customers in India. $\mathrm{He}$ has been teaching since November 2000 Currently, he is a Professor in the Department of Electronics and Communication Engineering, Gojan School of Business and Technology, Redhills, Chennai, India. 